
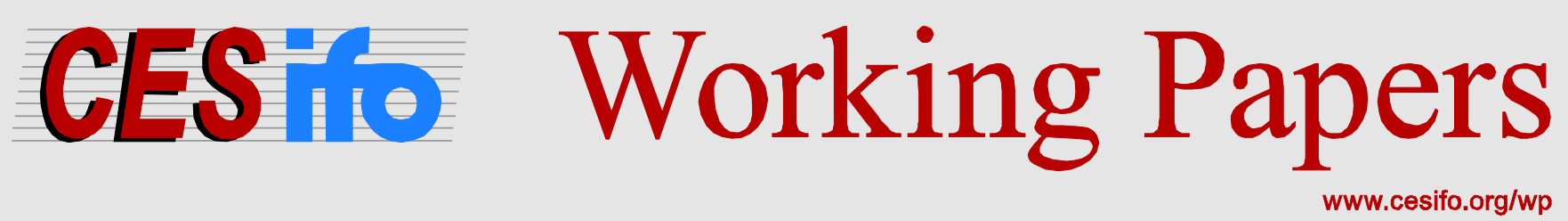

\title{
Cost Performance on the Norwegian Continental Shelf
}

\author{
Sindre Lorentzen \\ Petter Osmundsen
}

\author{
CESIFO WORKING PAPER NO. 6153 \\ CATEGORY 9: RESOURCE AND ENVIRONMENT ECONOMICS \\ OCTOBER 2016
}

An electronic version of the paper may be downloaded

- from the SSRN website:

- from the RePEc website:

- from the CESifo website:

WwW.SSRN.com

Www.RePEc.org

www.CESifo-group.org/wp 


\title{
Cost Performance on the Norwegian Continental Shelf
}

\begin{abstract}
The oil and gas sector plays a crucial role in the Norwegian economy. It accounts for a very large proportion of gross domestic product, government revenues, investment and exports. A sharp fall in oil prices has had a significant impact on the economy and focused great attention on the cost side of the sector. Enhancing cost efficiency and curbing cost overruns now top the agenda. It is not difficult to find examples of projects suffering extensive cost overruns. What factors underlie these overruns? Media coverage might easily give the impression that Norway's oil and gas sector is suffering from a lack of ability and competence to plan and execute projects to budget. Is this reputation deserved? Does the oil sector perform more poorly in Norway than in other producer nations? Can we see learning effects? How do the Norwegian and the international oil industry compare with other industries with respect to cost performance?
\end{abstract}

JEL-Codes: D220, D240, G310.

Keywords: cost overrun, petroleum industry, experience, comparison.

Sindre Lorentzen University of Stavanger Norway - 4036 Stavanger sindre.lorentzen@uis.no
Petter Osmundsen

University of Stavanger

Norway - 4036 Stavanger

Petter.Osmundsen@uis.no 


\subsection{Introduction}

An unusually long boom lasting more than a decade resulted in a sharp rise in costs for the oil industry in Norway and other producer countries. Combined with a steep drop in prices, this has presented major economic challenges for the petroleum sector and the oil producers and has prompted more attention to be paid to the cost side.

The literature on cost overruns in the oil and gas sector contains a number of examples of qualitative case studies. The investment commission (Norway's Official Reports, NOU 1999:11), for example, considered 13 oil and gas projects on the Norwegian continental shelf (NCS) between 1994 and 1998. Norway's Office of the Auditor General (Document no 3:8, 2001) followed up the investment commission's work on three projects in 1995-96, and the Norwegian Petroleum Directorate (NPD) conducted a similar study of a further five developments in 2006-08. These studies provide detailed and interesting insights into the projects assessed. Another advantage with this approach is that the subjects are relatively recent and typically large and important. On the other hand, the studies are often based on a sample which is too limited - in duration and in the number of observations - for overall conclusions to be drawn. A sampling distortion also occurs because the projects chosen for assessment are usually those with the biggest overruns. Without conducting an empirical study of a more comprehensive selection of projects, identifying the general trend on the cost side for oil and gas projects in Norway presents a challenge.

A review of the literature on cost overruns reveals that surprisingly few studies attempt to take an empirical approach to the subject. On the other hand, a number of empirical studies from the NCS analyse key components of development costs. Drilling can represent up to 50 per cent of these. Important elements here are rig rates and drilling speed. Skjerpen et al (2015) develop a model for rig rate formation on the NCS, while Osmundsen et al $(2010,2012)$ analyse the development of drilling speed in these waters. Cost overruns relate to aggregate investment and the business cycle in the sector. Bjørnland and Thorsrud (2016) look at developments in the oil industry compared with other sectors. Mohn (2008) and Mohn and Osmundsen (2008) analyse fluctuations in NCS exploration spending and number of exploration wells. Osmundsen et al (2006) and Aune et al (2010) analyse the market valuation of oil companies and how this influences their investment choices.

The present article seeks to correct this problem with the existing literature by empirically mapping cost overruns and in oil and gas operations on the NCS. That prompts us to ask the following questions.

1) How extensive are cost overruns in Norwegian oil and gas projects?

2) Have overruns in oil and gas projects on the NCS decreased over time - can we see learning effects?

3) How do overruns in oil and gas projects on the NCS compare with those in other geographical areas and industries?

4) What effect does experience have on overruns?

The article is structured as follows. The data set utilised is presented and described in section 2 . Section 3 analyses the statistical distribution of cost overruns, and compares them with other geographical areas and sectors. An econometric analysis is undertaken in section 4 in order to discuss possible drivers of overruns in more detail. Section 5 draws conclusions. 


\subsection{Data}

All data presented in this article are taken from publicly available sources. Table 1 presents a list of the various sources which the data set is based on. These data sets contain different degrees of detailing and included variables, so sample size will depend on the relevant analysis.

Table 1: Data sources

The various sources which the article's data set is based on.

\begin{tabular}{lcl}
\hline \multicolumn{1}{c}{ Source } & Period & \multicolumn{1}{c}{ Observations } \\
\hline NPD Fact Pages (2015) & $1971-2015$ & 109 oil and gas fields \\
NPD (2013) & $2006-2008$ & 24 projects \\
Auditor General (2001) & $1995-1996$ & 3 projects \\
Merrow (2006) & $1995-2010$ & 130 projects \\
Ernst \& Young (2013) & $2000-2013$ & 365 projects \\
Society of Petroleum Engineers & $1970-1980$ & 22 projects \\
Norway's national budget (2000-13) & $2000-2013$ & 80 projects \\
Investment commission (1991) & $1994-1998$ & 13 projects \\
Flyvbjerg (2014) & & 19 megaprojects \\
Flyvbjerg et al (2002) & $1910-1998$ & 258 projects \\
Sovacool et al & $1936-2014$ & 401 projects \\
\hline
\end{tabular}

\subsection{Cost overruns}

Cost overruns are an essential criterion for evaluating project execution. Much insight can be acquired by analysing them. However, it should be emphasised that a one-side concentration on costs is not optimal in a project evaluation. Other criteria are also essential for obtaining a correct perspective.

A cost overruns is defined here as the inflation-adjusted relative difference between the estimated and actual cost of a project. In line with the literature, the last available cost estimate before the project was sanctioned is taken as the starting point for the calculation. This ensures that the cost overrun is relevant for evaluating the decision aspect, but it must be stressed that this definition can give an inaccurate impression of the level of cost overruns in cases where major changes occur during the project. Cost overruns are a complex concept, and can result from a number of different factors which interact in complicated ways. The concept is informative not only about the ability of project managers to keep to budget, but also about the quality of project planning ahead of execution. Where the latter is concerned, overruns can be regarded as a cost estimation distortion. Given that a company is profit maximising, has limited capital and has a portfolio of potential projects in which to invest, faulty cost estimation could result in suboptimal resource allocation since the profitability ranking might be altered. Overruns can thereby be a source of financial loss to the company in so far as they represent a cost estimation distortion. However, such overruns are not equivalent to estimation distortions. Since costs are estimated in relation to a specific project, any and all changes to the plans will invalidate the original cost estimate. We can conclude that overruns, certeris paribus, are undesirable - in other words, assuming no changes are made to the plans. Should project changes occur along the way which would have a positive effect on production, regularity and so forth, that would not necessarily be the case. The reality is often a blend of changes and genuine overruns, which makes this a demanding field for analysis.

The rest of this section is structured as follows. Section 3.1 presents and analyses the statistical distribution of cost overruns in oil and gas projects on the NCS. The temporal development in 
overruns is inspected in section 3.2. Section 3.3 compares the results from section 3.1 with oil and gas projects in other geographical areas and with other industries and sectors.

\subsection{Statistic distribution of cost overruns}

Anecdotal observations of high cost overruns could be interesting objects for qualitative case studies, but are in themselves of limited use in efforts to establish the overall characteristics of the underlying data-generation process. Inspection of the statistical distribution of overruns are interesting for two main reasons. First, the statistical distribution - approached through histograms and density distributions - provides a good overview of the scope and characteristics of the cost overruns. Second, the statistical moments of the distribution are informative about the root cause of the overruns.

Table 2: Categorisation of underlying drivers for cost overruns A categorisation of theories concerning cost overruns (Flyvbjerg, 2002).

\begin{tabular}{lllc}
\hline Category & Mean & Skew & Convergence \\
\hline Bad luck or error & $\mu=0$ & $s=0$ & $\lim _{t \rightarrow \infty} \mu_{t}=0$ \\
Optimism bias & $\mu>0$ & $s>0$ & $\lim _{t \rightarrow \infty} \mu_{t}=0$ \\
Strategic reporting & $\mu>0$ & $s>0$ & $\lim _{t \rightarrow \infty} \mu_{0}=\mu_{t}$ \\
\hline
\end{tabular}

To investigate the latter, Flyvbjerg et al (2006) postulate that theories on the underlying drivers of cost overruns can be divided into three categories with distinctively different predictions for the moments of the statistical distribution of the overruns. These are bad luck or error, optimism bias and strategic reporting. In the first category, stochastic processes will almost always be present when a project is implemented. We should therefore expect a project's realised costs to be sum of cost estimates and symmetrical white noise, so that the statistical distribution is symmetric and distributed around the cost estimate. If bad luck or error is the underlying explanation for the overruns, such a characteristic should be evident - mean and skew for the overruns are equal to zero. Furthermore, constant improvements in estimation techniques mean that the overruns should converge to zero over time. With the second category, cognitive misapprehensions and bias can lead to overoptimism at the planning stage. This will imply a positive mean and skewness for the distribution of overruns. Research has contributed a great deal to the identification and increasingly to the communication of sources of cognitive pitfalls. The expectation should therefore be that the negative effects of overoptimism ought to decline over time. Finally, in the third category, political pressure and the principal-agent problem could provide incentives to underestimate project costs deliberately. Under such conditions, a form of inverse Darwinism can arise which actively selects projects which will give rise to high overruns rather than those which are estimated more accurately. Given that the underlying incentives are unchanged, it can be postulated that the central moment in the overrun's statistical distribution will not converge towards zero.

With a clearer understanding of the insight which is obtainable from the cost overrun's statistical distribution, the actual position on the NCS can now be addressed. Figure 2 presents a histogram and an estimated density plot for overruns in 158 projects executed on the NCS between 1970 and 2013.

Figure 1: Distribution of cost overruns in oil projects on the NCS between 1970 and 2013 


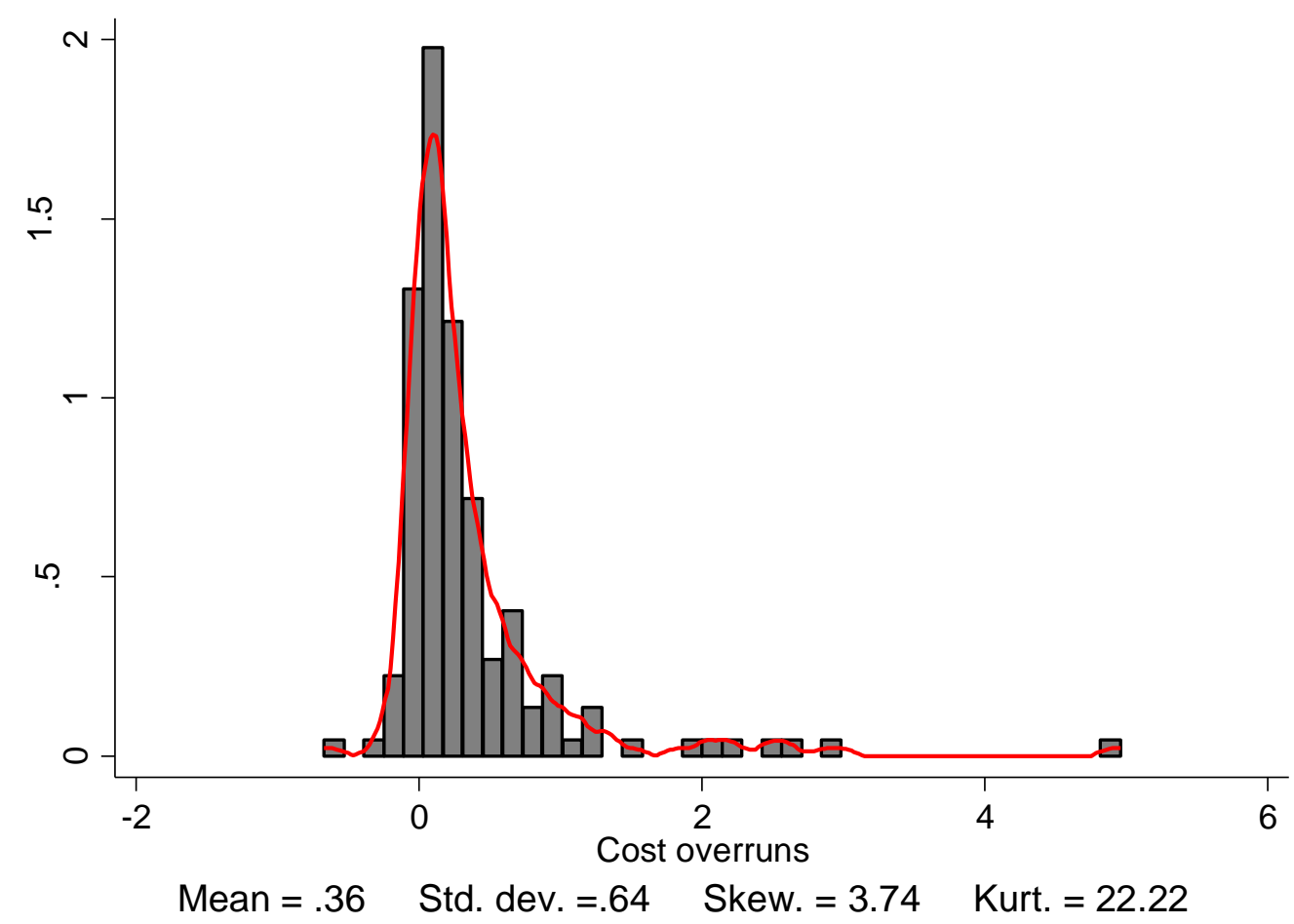

As illustrated in Figure 1 and Table 2, the mean overrun in the data set is substantially higher than zero (36 per cent). Furthermore, there appear to be a considerable standard deviation (64 percentage points), positive skewness (3.74) and leptokurtosis (22.22). In other words, the position for cost overruns is not optimal if the objective is unbiased estimates - providing, of course, that changes during the course of the project are ignored. Where Flyvbjerg's predictions of the root causes for overruns are concerned, support is found for optimism bias and/or strategic reporting on the basis of the observed mean and skewness in the distribution. How far this represents overoptimism based on cognitive bias or conscious distortion in the form of strategic reporting cannot be determined without inspecting the temporal stability of the statistical moments of the overruns. However, the conclusion concerning the presence of optimism or strategic reporting needs to be tested more extensively before a conclusion can be reached. An objection to using backward induction is that an underdetermination problem could arise if Flyvbjerg's categorisation is not mutually exclusive and collectively exhaustive - an alternative empirically equivalent theory could be the actual underlying driver for the overruns. Considering that the overrun is a continuous variable in the interval $[-1, \infty)$, for example, it is unreasonable to expect that a statistical distribution would not contain a certain degree of positive bias because of black swans in the right-hand tail. It is also the case that, while clear limits exist to how much of the costs can be cut in practice in relation to the estimated development bill (considerably below 100 per cent and usually only 10 per cent), overruns of several hundred per cent are fully possible. That also argues against a symmetrical cost distribution, but instead for a relatively long right-hand tail.

Table 3: Overall statistics for cost overruns

\begin{tabular}{lcccccc}
\hline Variable & Mean & Standard dev & Min & Max & Skew & Kurtosis \\
\hline Cost overrun & 0.36 & 0.64 & -0.67 & 4.95 & 3.74 & 22.22 \\
\hline
\end{tabular}




\subsection{Development of cost overruns}

According to Flyvbjerg's categorisation of theories on the root causes of cost overruns, the various theories yield different predictions for the temporal development of the overruns. An indication of the underlying cause of the overruns can thereby be obtained by studying development over time. See Table 2. In Figure 2 (a), overruns are plotted against time and a regression line estimated. Two distinct regimes in the data set emerge from the graph, one for 1970-84 and another for 1985-2015. A standard $t$ test with robust standard error for the first regime indicates that this is a significant ( $p$ value $=0.094$ ) and declining trend for the overruns. It might therefore appear that overruns in general fell as experience was accumulated. However, a corresponding test for the second regime is unable to reject the null hypothesis of no significant connection between time and overruns. No indication is thereby found during the second regime of any learning effect in the form of accumulated experience. Based on Flyvbjerg's categorisation, assessing the regimes separately should have yielded indications of overoptimism in the first and strategic reporting in the second. Thus, the mean cost overrun of 36 per cent for the overall sample might be misleading as disaggregating into the two established regimes yields an average cost overrun of 74 per cent in the first and 29 in the second. Despite the lack of any significant changes to the cost overruns during the second regime, the average overrun will be sensitive to the sample selection. This characteristic of the data is illustrated in Figure 2 (b) which compares the recursive and rolling average cost overrun. Again, that is under the unrealistic assumption that no changes occur during the project. An increased scope of work - such as greater process capacity, for example - and the implementation of new technology would modify reported overruns.

Figure 2: Development of cost overruns in oil and gas projects between 1970 and 2013 Development in cost overruns in oil and gas projects on the NCS between 1970 and 2013. Subfigure (a) presents a spread plot with a predicted regression line for each regime. Sub-figure (b) presents the development in average overruns measured both recursively (with standard deviation) and in terms of the rolling average of different selected durations.

(a) Cost overruns

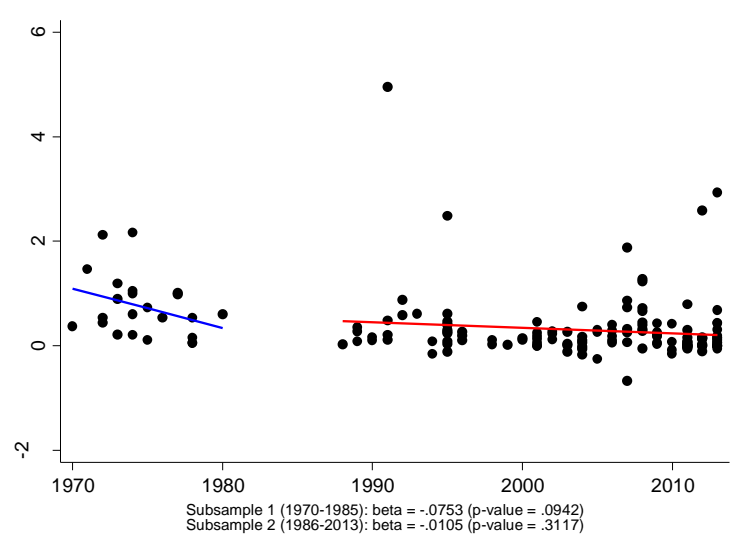

(b) Average cost overruns

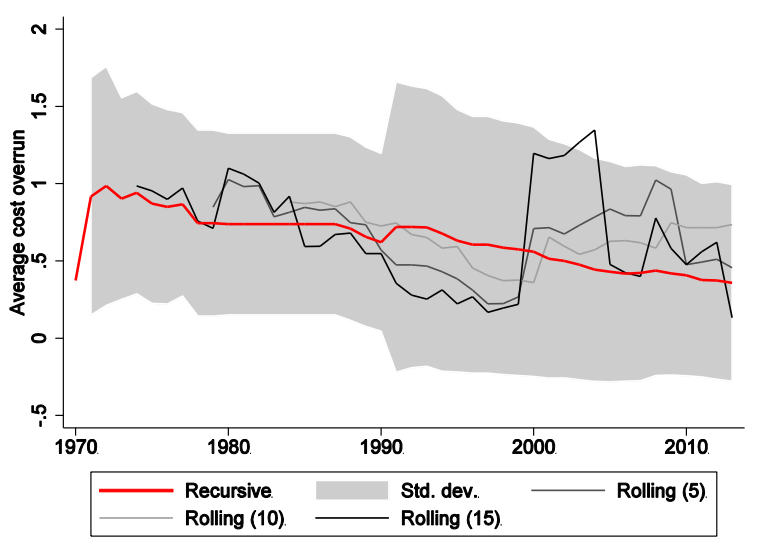

Almost 30 years without significant improvement in cost overruns is perhaps a disheartening result, but potential sources of effort may reduce the learning effect. First, the NCS covers a large area with varying meteorological, environmental and geological conditions. It could thereby be argued that experience from a specific area of the NCS is not relevant elsewhere. To illustrate this point, the NCS has been disaggregated into smaller areas. See Figure 3 (a). This shows noticeable differences in accumulated area experience for any given point in time between the various areas. Second, project 
operators may not be homogenous in terms of experience. For instance, variability could exists between the number of operator licences each company has held and thereby also in their experience on the NCS. Furthermore, Figure 2 (b) illustrates that new operators without earlier experience from the NCS regularly enter the scene. It might be reasonable to imagine that a company with far more licences than another (certeris paribus), and with a continuous process of development projects on the NCS, would tend to have fewer overruns. The entry of new players would thereby help to maintain overruns at a given level. Third, a non-linear relationship may exist between accumulated experience and cost overruns. A relevant possibility is that more experience may show a declining marginal effect. The convergence of overruns to zero as time moves towards infinity may be rapid initially and then slow down. Fourth, it is conceivable that differences in technology are a crucial variable for uncertainty and thereby also for overruns. Innovation and technological advances may make earlier experience irrelevant. A more extreme version of this argument is that each project is so idiosyncratic that the basis for learning from others is limited. New technology may also be a factor which restricts learning.

Figure 3: Operator and area experience

Experience on the NCS. Sub-figure (a) presents the number of active oil and gas fields in each sector of the NCS, with SNS = southern part of Norway's North Sea sector, MNS = central North Sea, NNS = northern North Sea, $\mathrm{NoH}=$ Norwegian Sea and BS = Barents Sea. Sub-figure (b) presents the number of new operators without earlier experience from the NCS.

\section{(a) Area experience}

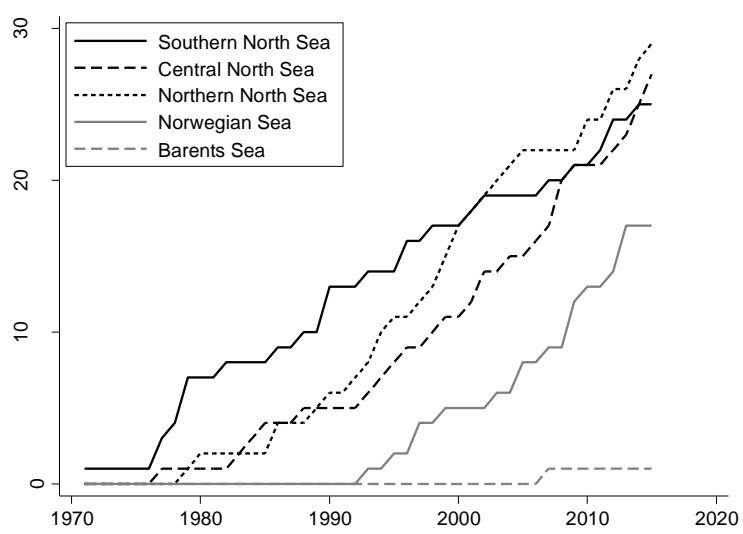

(b) New operators

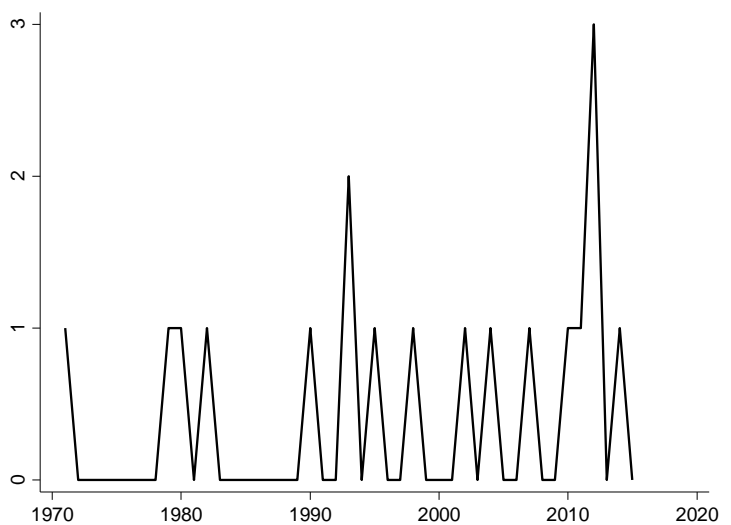

Finally, the motivation underlying the operator's decision behaviour may vary. Much of the basis for analysing cost overruns assumes that the project manager is a rational utility maximiser. It could be easy to believe that this is the equivalent of exercising cost-minimisation behaviour during project execution. However, costs are only part of the decision basis. Under the axiomatic assumptions, 
project selection will be based on discounted cash flows and the decision will thereby be a combination of costs and revenues. It is conceivable that the opportunity to reduce costs tends to extend execution time and thereby postpones revenues. Given the time value of cash flows, a balance might have to be struck which makes it optimal to focus on rapid project execution rather than keeping to budget. This argument could appear sensible from theoretical and practical perspectives, but verifying it empirically is likely to be challenging.

Figure 3 shows developments in oil prices. Oil prices have an obvious effect on the revenue side. A sufficiently high increase could make cost overruns relatively less relevant. A quick start up of production and high and regular production could be the priority. Similarly, a sufficiently steep fall in the oil prices makes it highly relevant to stick to the budget on costs or if possible to cut cost. It could thereby be argued that oil prices exert a big influence on where attention is concentrated during project execution.

Figure 4: Development in crude oil prices Price trends for crude oil (European Brent). Source: Datastream

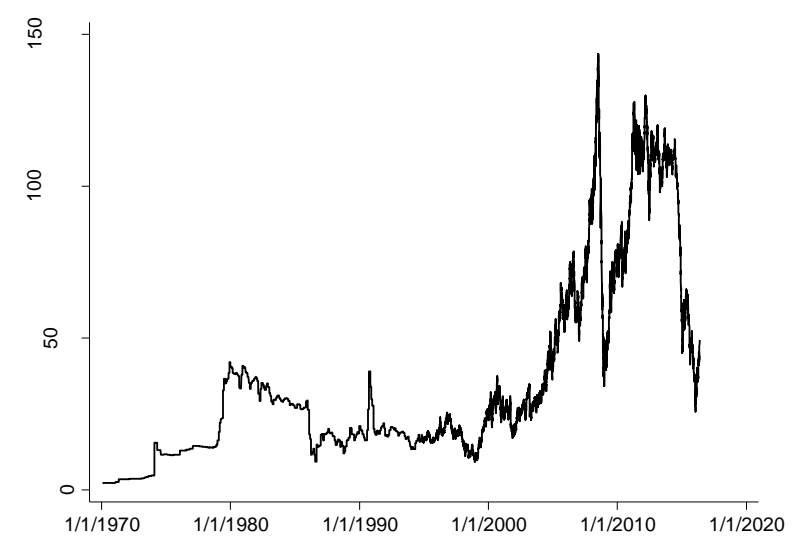

\subsection{Comparison across geographical areas}

The scale of cost overruns in petroleum projects on the NCS is possibly unedifying if the goal is unbiased estimates. While deviation from a unbiased and symmetric statistical distribution for overruns is an empirical fact in this data set, how does Norway perform compared with oil and gas projects in other countries? Results are presented here from four studies as the basis for a comparison: Merrow (2011), Ernst \& Young (2013), Flyvbjerg (2002,2003 and 2004) and Sovacool et al (2014). 
Merrow (2011) presents an extensive data set for megaprojects - involving an investment larger than USD 1 billion inflation-adjusted to 2010 - spread over large parts of the world. This set comprises 315 projects implemented between 1995 and 2015. Of these, 130 are classified as oil and gas production. Merrow describes the outcome of a project as a binary variable - successful or unsuccessful. Projects conducted with a cost overrun exceeding 25 per cent are characterised as unsuccessful. As Table 4 shows, 78 per cent of the oil and gas projects were unsuccessful in terms of cost overruns. They were realised with an average overrun of 33 per cent. That is fairly similar to the average of 36 per cent for oil and gas projects on the NCS. Since Merrow's figure relates only to the unsuccessful category, however, the aggregate overrun in Norway, applying the same method, will be larger. Applying the same procedure to the figures for the NCS shows that 40 per cent of the projects there were unsuccessful, with a conditional overrun of 80 per cent. Successful projects on the NCS had a conditional overrun of 5.36 per cent. On the basis of these figures, oil and gas projects on the NCS might appear to underperform compared with the rest of the world. Some conceivable sources of error are differences in the time periods covered by the two data sets. While figures for the NCS go back to 1970, the set presented by Merrow only covers 15 years of the recent past. As revealed in section 3.2, overruns on the NCS since 1985 were smaller than before. Excluding data which do not fall within the time frame of the Merrow study yields different figures for the NCS. The average overrun for unsuccessful projects now lies at 41 per cent. Another possible source of error is that Merrow's data set consists entirely of megaprojects, while the figures from the NCS is a mixture. However, the possible effect of this is ambiguous.

Table 4: Outcomes for megaprojects (Merrow, Independent Project Analysis)

\begin{tabular}{lccc}
\hline \multicolumn{1}{c}{ Evaluation criteria } & Threshold for fiasco & $\begin{array}{c}\text { Aggregated } \\
\text { sample } \\
\mathbf{( 6 5 \% )}\end{array}$ & $\begin{array}{c}\text { Oil and gas } \\
\text { production (78\%) }\end{array}$ \\
\hline Cost overruns & $>25 \%$ & $40 \%$ & $33 \%$ \\
Cost competitiveness & $>25 \%$ & $\mathrm{NA}$ & $40 \%$ \\
Execution delays & $>25 \%$ & $28 \%$ & $>28 \%$ \\
Time competitiveness & $>50 \%$ & $15 \%$ & $<15 \%$ \\
\hline
\end{tabular}

Note: The average outcome of each of the evaluation criteria is contingent on the project being unsuccessful.

Ernst \& Young (2013) presents a similarly extensive data set comprising 365 megaprojects at a global level. Unlike Morrow, these figures are not aggregated and accordingly permit differences in cost overruns to be observed for geographical regions. As Table 5 shows, the average overrun (regardless of area) is 64 per cent and overruns occurred in 51 per cent of the cases. It could therefore appear that the incidence of overruns in this data set is considerably higher than for projects on the NCS. On the other hand, the distribution in the Ernst \& Young set is far more symmetric than for the latter. Furthermore, Table 5 reveals regional differences in the overruns. The differences become smaller when the NCS is compared with North America and Europe. The sources of error which applied to the data from the NCS and Merrow are also valid here. The Ernst \& Young data set covers a far shorter period of time and consists exclusively of megaprojects. However, correcting the data set for the NCS so that the time frame corresponds with Ernst \& Young is not possible without reducing the set too sharply.

Table 5: Outcomes for megaprojects (EY) 


\begin{tabular}{lccc}
\hline \multicolumn{1}{c}{ Area } & $\begin{array}{c}\text { Frequency of cost } \\
\text { overruns }\end{array}$ & Frequency of delays & Average cost overrun \\
\hline North America & $58 \%$ & $55 \%$ & $51 \%$ \\
Latin America & $57 \%$ & $71 \%$ & $102 \%$ \\
Europe & $53 \%$ & $74 \%$ & $57 \%$ \\
Africa & $67 \%$ & $82 \%$ & $51 \%$ \\
Middle East & $89 \%$ & $87 \%$ & $68 \%$ \\
Asia-Oceania & $68 \%$ & $80 \%$ & $57 \%$ \\
\hline Aggregated & $\mathbf{5 1} \%$ & $\mathbf{7 3} \%$ & $\mathbf{6 4} \%$ \\
\hline
\end{tabular}

One of the problems with the data obtained from Merrow and Ernst \& Young is that the analyses are largely confined to an inspection of average cost overruns. If interest focuses on the average underlying statistical distribution of the overruns, little insight can be gained by exclusively studying first-order moments. Studies by Flyvbjerg et al (2002, 2003 and 2004) can provide more detailed insight. They present data from what was then the first significant study of cost overruns for transport infrastructure. Using figures from 258 projects between 1910 and 2000 in 20 different countries allows them to make several insightful observations. Nine out of 10 projects end up with overruns, averaging 28 per cent with a standard deviation of 38 percentage points. However, the average overrun varies substantially between different project types. Furthermore, overruns do not appear to vary significantly over the past 70 years. See Table 6 for an overview.

Table 6: Cost overruns in transport infrastructure projects

Overall statistics for 258 transport infrastructure projects between 1910 and 2000 . The figures are taken from Flyvbjerg et al (2002).

\begin{tabular}{lccc}
\hline Type of project & Observed & Mean & Standard deviation \\
\hline Railway & 58 & $45 \%$ & 38 \\
Bridge/tunnel & 33 & $34 \%$ & 62 \\
Road & 167 & $20 \%$ & 30 \\
All projects & 258 & $28 \%$ & 39 \\
\hline
\end{tabular}

Based on the statistical moments of the cost overruns from oil and gas developments and transport infrastructure projects, no overwhelming differences emerges in the scale of overruns between these sectors. This point can be further illustrated by comparing the statistical distributions for both data sets. Figure 5 (a) compares the same density plots for the two sectors. It emerges that both distributions have the same characteristics in terms of mean and skewness - both are significantly positive. However, some noteworthy differences should be pointed out. Oil and gas projects appear to be more heavily concentrated around the mode of their distribution than those for transport infrastructure. Furthermore, the former have a longer right-hand tail while the latter have a larger number of observations below zero. In other words, oil and gas projects feature more extreme overrun cases. The most drastic of these is 496 per cent, almost five times the original estimate. Although that might seem extreme, many examples of even greater overruns are to be found elsewhere. Figure 5 (b) presents the statistical distribution for a selection of the most disastrous megaprojects in history (Flyvbjerg, 2014). However, it should be emphasised that the literature draws a distinction between normal and megaprojects.

Figure 5: Comparison on cost overruns between sectors 
Sub-figure (a) compares estimated density plots (Epanechnikov kernel functions) for cost overruns in public transport and private petroleum projects. The former set comprises 106 observations between 1910 and 1998, while the latter covers 158 observations between 1970 and 2015. Data for the transport projects were extracted from Flyvbjerg et al $(2002, p 38)$ through digitalisation with an image processing algorithm. This process can introduce a negligible amount of random noise in the data. Sub-figure (b) presents a selection of "disastrous" megaprojects. The data are taken from Flyvbjerg (2014).

(a) Oil/gas and transport infrastructure

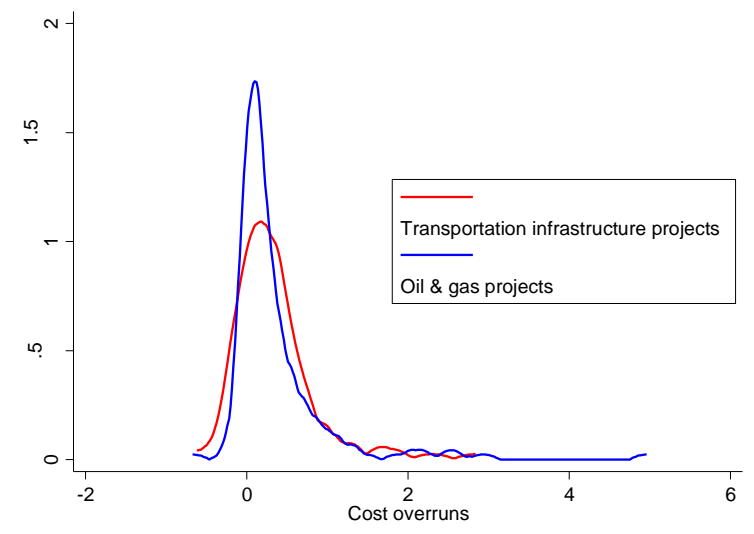

(b) Disastrous projects

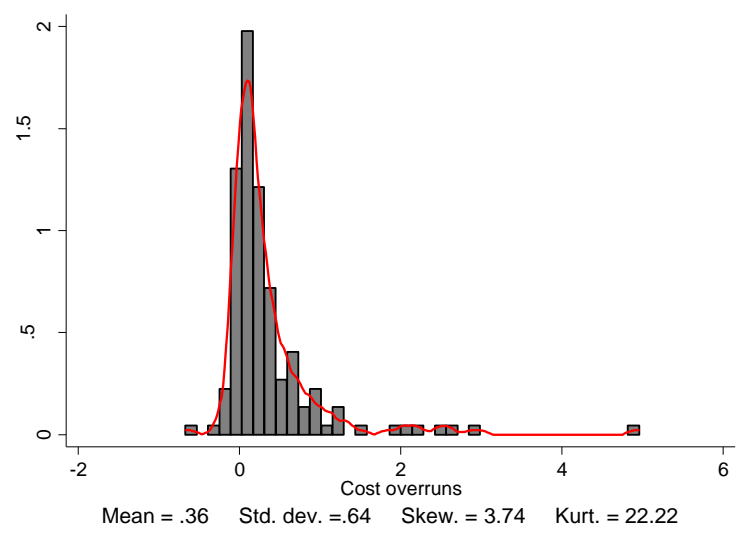

Based on figures acquired and published by Sovacool et al (2014), a corresponding analysis of the statistical distributions can be performed. Sovacool presents a data set comprising 401 different projects concerning electricity generation and associated infrastructure in 57 different countries in 1936-2014. As Figure 6 shows, projects relating to hydropower, nuclear energy, thermal power stations, wind farms, solar farms and transmission lines display a statistical distribution which corresponds well with oil and gas projects on the NCS. Both have a positive mean and skewness, substantial standard deviation and leptokurtosis. An inspection of the first order moment reveals that the average cost overrun is significantly lower in oil and gas projects ( 36 per cent) compared with electricity developments (66 per cent). That reflects a substantially longer right-hand tail for the latter, which is to be expected since they involve a far larger number of observations and a much longer time frame. However, too much emphasis should not be given to the averages, since the mode of the distributions appears to coincide. All in all, we have good indications that cost overruns in the oil and gas sector are not that different from either transport infrastructure or electricity generation. Such overruns appear to be a phenomenon found across both sectors and geographical regions.

Figure 6: Cost overruns for electricity infrastructure Cost overruns for 401 electricity infrastructure projects between 1936 and 2014 in 57 different countries. Sub-figure (a) presents the statistical distribution of the overruns with a histogram and density plot, while development over time is shown in sub-figure (b) by a density plot with a regression line. Sub-figure (c) compares a density plot for electricity infrastructure projects with oil and gas developments.
(a) Statistical distribution
(b) Spread plot 

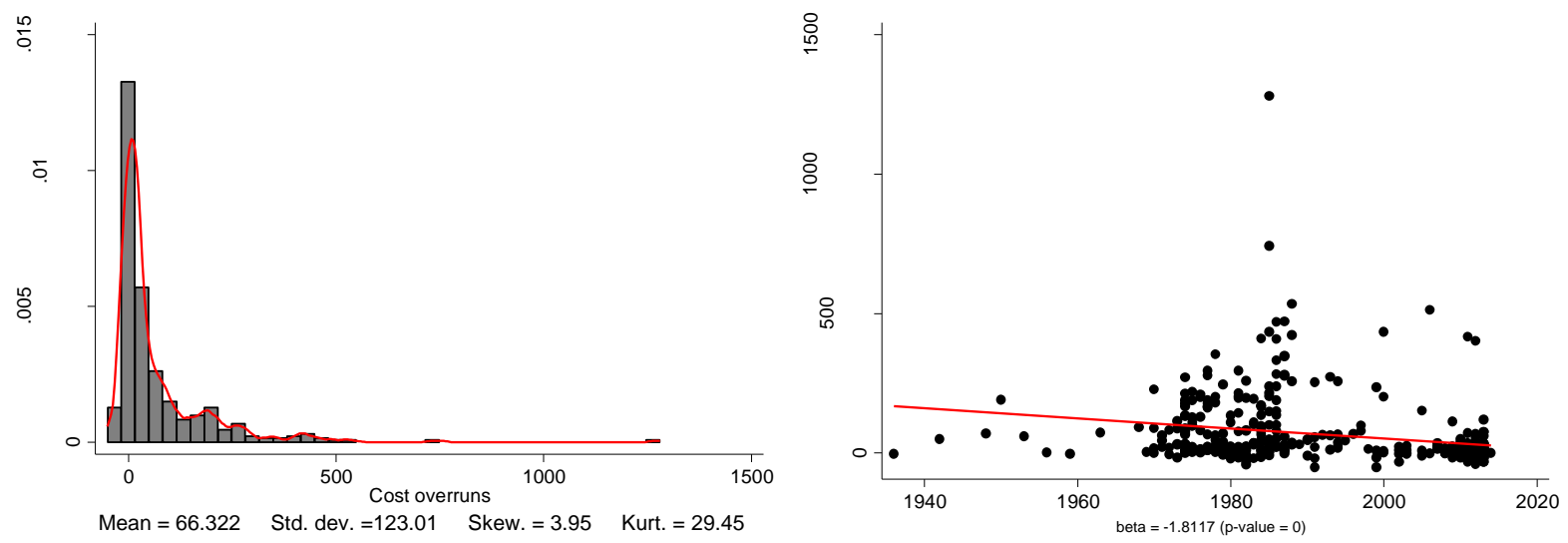

(c) Electricity infrastructure and oil/gas projects

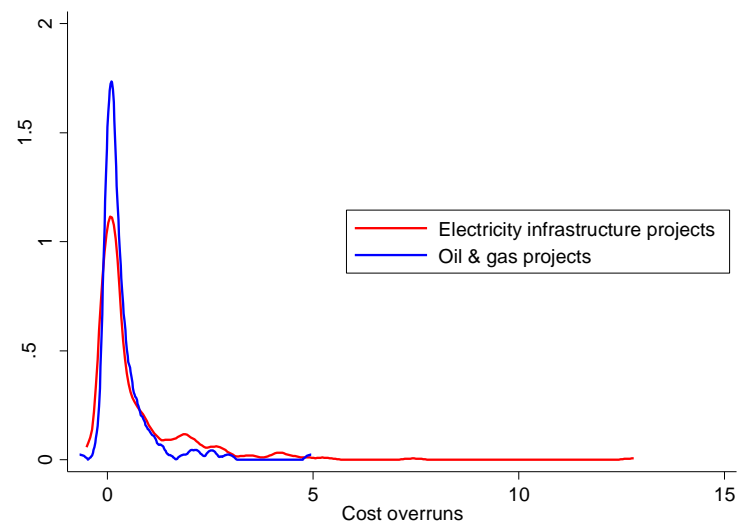




\subsection{The effect of experience}

Many factors could potentially affect the scale of cost overruns. One potential factor is area experience. The geographical site of the project could affect its execution in a number of ways. Location determines such aspects as depth, temperature and pressure. If overruns are primarily driven by uncertainty, area experience could have a direct effect on the project team's knowledge of geological conditions, for example, and thereby also exert an influence on overruns.

Figure 7: Effect of area experience

A spread plot with a predicted regression line is presented in order to illustrate the effect of area experience on cost overruns for oil and gas projects in the Norwegian North Sea between 1970 and 2013. Area experience is defined here as the accumulated number of projects begun.

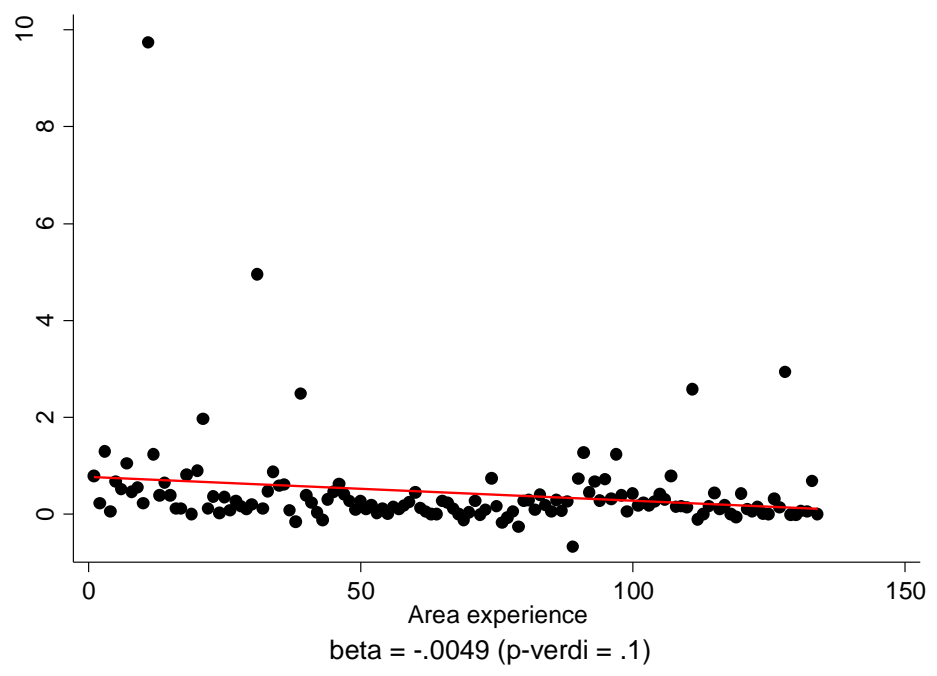

Figure 9 presents the empirical connection between area experience and cost overruns for Norwegian North Sea projects between 1970 and 2013. Area experience is defined here as the accumulated number of projects initiated. As the graph indicates, a relationship with marginal statistical significance exists between these factors. It might thereby appear that cost overruns tend to decline as experience accumulates. This finding builds on the assumption that learning is shared between projects. The likelihood of such cross-fertilisation is greater where the same operator company is responsible for several projects. A certain level of knowledge transfer is nevertheless possible even between different players, not least through the partnership of different oil companies in each licence. The entry of new players to the (North Sea) market will probably reduce the observed effect of area experience. Furthermore, since such experience is not normally achieved until the project has been executed, utilising developments which are under way rather than completed will probably also reduce the observed effect. Despite these downsides, the relationship is significant. A correction for new entrants and a redefinition to completed projects would probably strengthen the effect. Restrictions on data availability mean that these possibilities cannot be analysed in more detail. 


\subsection{Conclusion}

A sharp fall in oil prices has concentrated greater attention on costs on the NCS. This article studies cost trends in these waters.

The literature on cost overruns in the oil and gas sector contains a number of examples of qualitative case studies. Their advantage is that they permit in-depth examination of individual projects, usually large and recent ones. On the other hand, these studies are often based on samples which are too restricted in time and number of observations for overall conclusions to be drawn. The selection is also skewed because attention is usually concentrated on the projects with the biggest overruns. This article conducts an empirical analysis of an extensive sample of projects in order to identify the general trend for costs in Norwegian oil and gas projects. The study is based on figures from the NPD and several other sources, totalling 158 development projects between 1971 and 2015.

The average cost overrun in the data set is 36 per cent - under the unrealistic assumption that no changes are made during the course of the project. An increased scope of work - such as larger process capacity, for example - and the adoption of new technology would modify reported overruns. It is conceivable that opportunities to reduce costs tend to extend implementation and thereby postpone revenues. Given the time value of cash flows, a balance may need to be struck where the optimal approach is to concentrate attention on rapid project execution rather than staying within budget.

We find that cost overruns on the NCS after 1985 are lower than before. The analysis suggests that overruns tend to decrease as experience is built up, where experience is defined as the accumulated experience in various regions of the NCS.

Studies of cost overruns in other producing countries do not provide a basis for claiming that the NCS stands out in a negative way. Nor do NCS overruns or overruns in other petroleum extraction countries differ from global investigations of overruns in transport and electricity infrastructure projects. 


\section{Sources}

Aune, F R, Mohn, K, Osmundsen, P, and Rosendahl, K E (2010). “Financial Market Pressure, Tacit Collusion, and Oil Price Formation", Energy Economics 32, 389-398.

EY (2013). Spotlight on oil and gas megaprojects. Ernst \& Young

Flyvbjerg, B (2014). "What you should know about megaprojects and why: An overview", Project Management Journal 45 (2), 6-19. Flyvbjerg, B, Holm, M S and Buhl, S (2002). "Underestimating costs in public works projects: Error or lie?", Journal of the American Planning Association 68 (3), 279-295.

Flyvbjerg, B, Skamris Holm, M K and Buhl, S L (2003). "How common and how large are cost overruns in transport infrastructure projects?", Transport Reviews 23 (1), 71-88.

Flyvbjerg, B, Skamris Holm, M K and Buhl, S L (2004). "What causes cost overrun in transport infrastructure projects?", Transport Reviews 24 (1), 3-18.

Hilde, C B and Thorsrud, L A (2016). "Boom or gloom? Examining the Dutch disease in two-speed economies", Economic Journal (forthcoming).

Merrow, E W (2011). Industrial megaprojects. Hoboken, NJ: Wiley.

Mohn, K (2008). "Efforts and Efficiency in Oil Exploration: A Vector Error-Correction Approach", The Energy Journal 30 (4), 53-78.

Mohn, $\mathrm{K}$ and Osmundsen, $\mathrm{P}$ (2008). "Exploration economics in a regulated petroleum province: The case of the Norwegian Continental Shelf", Energy Economics, 30,2,303-320.

Norwegian Official Reports (NOU) 1999:11. Analyse av investeringsutviklingen på kontinentalsokkelen.

Norwegian Petroleum Directorate Fact Pages (2016). http://factpages.npd.no/factpages/ [accessed: 27 February 2016].

Norwegian Petroleum Directorate (2013). "Vurdering av gjennomførte prosjekter på norsk sokkel”. 
Osmundsen, P, Asche, F, Misund, B and Mohn, K (2006). "Valuation of International Oil Companies", Energy Journal, 27, 3, 49-64.

Osmundsen, P, Roll, K H and Tveterås, R (2012). “Drilling speed - the relevance of experience", Energy Economics 34, 786-794.

Osmundsen, P, Roll, K, and Tveterås, R (2010). "Exploration Drilling Productivity at the Norwegian Shelf", Journal of Petroleum Science and Engineering, 73, 122-128.

Office of the Auditor General of Norway (2001). Dokument nr. 3:8 Riksrevisjonens undersøkelse av kostnadsoverskridelsene i feltutbyggingene Åsgard, Visund og Jotun.

Skjerpen, T, Storrøsten, H B, Rosendahl, K E and Osmundsen, P (2015). "Modelling and forecasting rig rates on the Norwegian Continental Shelf", discussion papers, Statistics Norway research department, No 832, December 2015.

Sovacool, B K, Gilbert, A and Nugent, D (2014). "Risk, innovation, electricity infrastructure and construction cost overruns: Testing six hypotheses", Energy 74, 906-917. 